\title{
Catholic priests' conceptualisation of scrupulosity: a grounded theory analysis
}

\author{
Margaret Hepworth ${ }^{\mathrm{a}}$, Laura M. Simonds ${ }^{\mathrm{b}}$ and Robert Marsh ${ }^{\mathrm{c}}$ \\ ${ }^{a}$ MHCOP, Burdett House, Mile End Hospital, Bancroft Rd, London E1 4DG, UK. Tel: \\ 0208121 5428. Email: Mog.Hepworth@eastlondon.nhs.uk \\ ${ }^{\mathrm{b}}$ Psychology Dept, University of Surrey, Guildford, Surrey, GU2 7XH, UK. Tel: 01483 \\ 686936. Email: 1.simonds@ surrey.ac.uk \\ ${ }^{c}$ Dept. Of Applied Social and Psychological Development, Salomons: Canterbury Christ \\ Church University, Broomhill Rd, Southborough, TN3 0TG, UK. Tel: 01892507619. \\ Email: robert.marsh@canterbury.ac.uk
}

Running Head: Priests' conceptualisation of scrupulosity

*Corresponding Author: Laura M. Simonds. Email: 1.simonds@ surrey.ac.uk 


\begin{abstract}
Scrupulosity is a manifestation of obsessive-compulsive disorder concerned with religious themes. It is unclear how religious leaders understand scrupulosity, the support they offer, or how they view collaboration with mental health practitioners. This study was designed to address these issues. Eleven Catholic priests took part in a semistructured interview based on a vignette describing a person with scrupulosity. Data were analysed using a grounded theory approach. Priests understood scrupulosity as a psychological problem that they felt unqualified to deal with but for which they could offer spiritual guidance. Scrupulous individuals were perceived as difficult to develop a supportive relationship with and were sometimes a challenge to priests' emotional wellbeing. Collaborative working between priests and mental health services was suggested as a way to address these issues, although priests recognised some difficulties in implementing this. Further research, with other religious groups and with people with scrupulosity, would be beneficial in order to expand the current conceptual framework.
\end{abstract}

Keywords: catholic, priests, scrupulosity, OCD, help-seeking 


\section{Introduction}

Scrupulosity is a manifestation of obsessive-compulsive disorder (OCD) characterised by persistent doubts (obsessions) and fears about sin, blasphemy and punishment from God, and compulsions related to excessive religious behaviour such as repeated praying and seeking reassurance about religious issues (Abramowitz, Huppert, Cohen, Tolin \& Cahill, 2002). Core features of scrupulosity, proposed by Miller and Hedges (2008), are excessive or inappropriate guilt, worry, doubt, rumination or observance regarding moral or religious practice; significant distress or impairment to functioning; and, ineffectiveness of reassurance or guidance from religious authorities. Cognitive models of OCD suggest that it is the appraisal of an obsession that prompts distress and neutralising activity (e.g. compulsions). The Obsessive Compulsive Cognitions Working Group (OCCWG, 1997) suggests that six belief domains underpin appraisals characteristic of OCD; these are beliefs regarding: personal responsibility, the consequences of one's thoughts, the need to control thoughts, the probability and severity of threat, the management of uncertainty, and perfectionism. Abramowitz et al. (2002) employ a similar 'over-importance of thoughts model' to suggest that scrupulous individuals perseverate about relatively minor moral dilemmas, resulting in a drive for perfectionism in religious observance and repetitive reassurance-seeking due to feelings of guilt and worry that such misinterpretation provokes.

Moral and ethical concerns are an enduring part of the conceptualisation of OCD. For example, Rachman and Hodgson (1980) conceptualised people with OCD as those of 'tender conscience'. A key appraisal process postulated by several authors, including Shafran, Thordarson and Rachman (1996), is 'morality thought-action fusion' - the 
notion that bad thoughts are equivalent to bad actions. Some biblical passages blur the boundary between thought and action, for example in the often cited verse: "you have heard that it was said 'Do not commit adultery'. But I tell you, anyone who looks at a woman lustfully has already committed adultery with her in his heart". (Matthew 5:2728). This presents a view in which moral purity may be judged against thought alone. People with scrupulous tendencies might be sensitive to such injunctions leading them to make fear-inducing judgments about all manner of apparently harmful thoughts being morally equivalent to actions. The limitations of a cross-sectional design notwithstanding, Nelson, Abramowitz, Whiteside and Deacon (2006) find support for the hypothesis that hyper-morality coupled with catastrophic misinterpretations might lead to the development of obsessional problems in religious individuals.

Scrupulous behaviours may appear to be enmeshed within the individual's religious life and have been reported to be at the extreme end of a continuum of religious behaviour (Tek \& Ulug, 2001). In attempting to distinguish 'authentic' faith expressions from psychopathology, Greenberg (1984) suggests focussing on the extent to which religious adherence is beyond required practice, a focus on getting observance to rituals 'right', interference with religious life (e.g. church attendance), and resemblance to OCD (e.g. repetition, reassurance-seeking). For example, Burt and Rudolph (2000) describe the case of an Orthodox Jewish woman with OCD who would doubt she had waited the required six hours between eating meat and dairy products. She was so afraid that she had contaminated her food with non-kosher products that she developed a fear of eating, resulting in rapid drastic weight loss. She also became obsessed with adherence to menstrual purity rituals and would seek reassurance from her rabbi. 
In order to initiate help-seeking, an individual must recognise they have a problem which may require some help, and they need to know whether such help is available and from where it might be accessed (Goldberg \& Huxley, 1992; Jorm, 1997). Additionally, an individual must feel that the help on offer is tolerable. The phenomenology of scrupulosity indicates that individuals, if they are likely to seek help at all, would do so from religious leaders rather than clinicians (Abramowitz et al., 2002; Miller \& Hedges, 2008). In support of this, a study of ultra-Orthodox Jewish psychiatric patients with OCD by Greenberg and Shefler (2002) found that religious sources were consulted for help with religious obsessions and psychologists/psychiatrists were consulted for non-religious obsessions. However, these authors did find that a sizeable proportion of the sample that had religious obsessions sought help initially from a psychologist/psychiatrist. As the authors point out, this finding may arise due to the sample being comprised of those who were in psychiatric treatment. Ciarrocchi (1998) observes that the most significant treatment challenge is engaging scrupulous clients, as they may find therapeutic procedures morally objectionable (e.g. exposure to blasphemous thoughts), or believe that therapists are ignorant of religious traditions, or fear that the therapist is attempting to convert them to anti-religious ways of thinking. Marsh and Low (2006), in drawing attention to issues involved in working therapeutically with religious individuals, suggest there may be a fear on the part of the client that the therapist might be hostile to his/her religious life and that this fear may be complicated in the presence of a religious therapist since this might create the potential for shame to be experienced by the client. 
An additional complicating factor is the potential ego-syntonic nature of scrupulosity. Whereas thoughts relating to morality in OCD are usually experienced as unwanted and unwelcome such concerns in scrupulosity, if they are part of an obsessivecompulsive personality problem, are not incongruent with the person's sense of self (Nelson et al., 2006). Similarly, scrupulosity often falls into the classification of 'overvalued ideas' and, as such, individuals may not resist such behaviour and actively avoid treatment (Ciarrocchi, 1998). Scrupulous concerns may not necessarily appear as inappropriate as their practices may be an exaggerated form of routine religious behaviour, such as moral rumination (Miller \& Hedges, 2008). It is clear, then, that there are considerable difficulties in engaging scrupulous individuals in therapeutic work. Given scrupulous individuals are likely to seek help from religious leaders initially, and that the latter might be working without psychological support, the impact of working with this group on religious leaders is an important but under-researched area. In a study of mental health generally, Leavey, Loewenthal and King's (2007) interviews with religious leaders from different faith groups suggest they are often required to support mental health problems but feel ill-prepared for this, resulting in caution, frustration, confusion and, sometimes, rejection. Whilst they recognise the limits of their expertise and are willing to refer to mental health services, they recognise that some parishioners will not accept help due to a desire to conceal or due to lack of insight. Although there is some literature from the United States (e.g. Benes, Walsh, McMinn, Dominguez \& Aikins, 2000; Edwards, Lim, McMinn \& Dominguez, 1999; McMinn, Aikins \& Allen Lish, 2003) on collaborative working between psychologists and clergy, Leavey et al. (2007) note that little is currently known about the experience and willingness of UK 
clergy to engage in collaborative working with mental health services or of how clergy deal with the mental health needs of their parishioners. As Greenberg and Shefler (2008) observe, the rationale for cooperation between clergy and mental health workers is abundantly clear in the case of religious OCD.

The present study aimed to develop a conceptual understanding of scrupulosity and its treatment, including collaborative working with mental health professionals, from the perspective of Catholic priests. To our knowledge, no study in the U.K. has addressed this issue. According to the 2001 census, Christianity is the most common religion within England and Wales. The Catholic Church estimates there are between four and five million Catholics in England and Wales with this number likely to increase due to migration from European countries such as Poland. Catholicism incorporates a number of rituals, such as repenting ones sins in the act of reconciliation (also known as 'confession'), which could be performed excessively. The act of reconciliation would be a crucial context for the expression of scrupulosity and is a situation in which priests are bound by the seal of confidentiality, limiting their sharing of complex issues with others. Additionally, Catholic teachings and precepts embody constructs such as thought-action fusion and perfectionism (Sica, Novara \& Sanavio, 2002). The focus on Catholicism in this study does not indicate a higher predisposition to scrupulosity in this denomination. Instead, it was felt important to develop a preliminary conceptual framework, one relevant to one of the largest denominations in Britain, that might then be assessed and expanded by the study of other religions and denominations.

Two broad research questions were addressed: 
1. How do Catholic priests understand scrupulosity?

2. What challenges do they identify in working with scrupulous individuals at an individual and collaborative level?

\section{Method}

\section{Design}

Semi-structured interviews were carried out with eleven Catholic priests. Theoretical sampling was used such that variables that might influence views on and experiences of working with mental health problems were taken into account, such as experience of working with mental health services or having experienced personal therapy. A vignette (Appendix 1) was developed describing a woman who exhibited common scrupulous behaviours. Vignettes are considered an effective method of eliciting attitudes (West, 1982) and a vignette was used in this study to provide priests with an opportunity to comment on scrupulosity without having to consider a specific individual known to them. This was considered vital given the seal of confidentiality. However, in practice, the vignette acted as a useful starting point for a more open discussion of individuals the priests were familiar with. A semi-structured interview schedule was developed which, although focussing on the vignette, allowed for this wider discussion. Previous studies have used vignettes to obtain data for grounded theory analysis (e.g. Burman, Stepans, Jansa \& Steiner, 2002; Neufeldt et al. (2006); Taylor, 2006; Thompson, Barbour \& Schwartz, 2003). A Catholic clinical psychologist was consulted to ensure the vignette and interview schedule used appropriate language. 


\section{Participants}

Potential participants were identified from a directory of priests within one diocese and from a website of priests in another diocese, both covering the South of England. Twenty-five priests were contacted by phone of which twelve agreed to participate. Those who agreed were sent a letter containing an information sheet and consent form. Those priests who refused to participate mostly did so due to work schedule constraints. One priest refused to participate as he felt this would break the confidentiality seal. One of the twelve priests who initially consented was unable to undertake the interview within the data collection time-frame and so could not be included. The characteristics of the eleven participating priests are given in Table 1. The sample included priests who trained before and after the changes in the church following the Second Vatican Council (19621965), which radically altered the way the Catholic Church presented itself and its theology. It also included priests who had undertaken personal psychological therapy, who had experience of working with mental health services (through offering input to psychiatric hospitals), and who had specialised counselling training. Two of the priests were university chaplains and one was a clinical psychologist (no longer practicing). All had received some psychology/counselling training in their studies. Nine priests worked within one diocese and two worked as part of a religious community whose ministry extended beyond individual diocese boundaries. Six of the priests reported experience of working directly with scrupulous individuals.

\section{INSERT TABLE 1 ABOUT HERE}




\section{Procedure}

All interviews were undertaken by the first author in a quiet office at each priest's parish. All of the participants consented to the interviews being recorded and each lasted between 60 and 90 minutes. Following an initial set of questions obtaining demographic data and building rapport, the participants read the vignette and participated in discussing the vignette through prompts from the interview schedule. Debriefing and time for further comments was provided at the end of the interview.

\section{Analytic Process and Quality Assurance}

Data were coded by the first author, with the co-authors providing quality assurance checks. Data was collected and analysed simultaneously, when possible, as recommended by Strauss and Corbin (1998). Analysis comprised two coding stages. The first stage involved open coding, where data were summarised and described by a short phrase. This could be the wording given by the participant (known as an 'in vivo' code). This enables the analyst to preserve meaning and ensure codes are grounded in the data. Then, focused coding was completed alongside, as well as after, open coding once more conceptual and interpretive codes arose. During this process, the analytic work was discussed between the first author and the co-authors to ensure the emergent account was grounded in the data. Additionally, the final analytic summary was distributed to all

participants for respondent validation (see Henwood \& Pidgeon, 2003). Four priests responded, three of whom reported the summary was interesting and largely congruent with their views and experience. 


\section{Findings}

A conceptual framework was developed that attempted to represent priests' views of scrupulosity and the challenges presented when working with scrupulous parishioners, both at an individual and collaborative level. Following Strauss and Corbin's (1998) recommendation, a core concept was identified that captured the essence of the findings, with all thematic categories being related to it. The core concept identified - 'a rigid and fearful view of self, God, and world' - represents how priests understood the characteristics and genesis of scrupulosity, and also the various challenges in managing this at the priest-parishioner and also the priest-mental health practitioner level. Three themes were subsumed within this core concept: (1) intrapersonal and interpersonal origins and consequences of the fearful worldview; (2) restoring a more balanced view of the self-religion relationship; and, (3) achieving an interface with mental health services. Each of these themes is discussed below in elaborating the core concept. Each theme comprises a number of subthemes.

\section{(1) Intrapersonal and interpersonal origins and consequences of the fearful worldview}

This theme captures priests' conceptualisation of scrupulosity, where it originates, and the consequences for the scrupulous person and their significant others. All of the priests viewed people with scrupulosity as having a fearful world view and, as a consequence, adhering to religion in an inappropriate way with the term 'obsessive' being used frequently. Scrupulous individuals were construed as seeing God and doctrine in overly restrictive ways and were characterised as having feelings of worry, fear and 
unworthiness. The subtheme vicious cycle reflects the idea that scrupulous individuals have fixed beliefs about sin that reflect an unhealthy view of religion and one that they are unable to break free from. It was suggested that such a view is associated with negative emotional and behavioural consequences: "has a very authoritarian concept of God which obviously gives rise to anxiety" $(\mathrm{P} 4)$ and: "going back time and time again to past sins" (P1). Priests spoke of the constant worry and fear that they felt people with scrupulosity experienced, both in relation to themselves and to others. Priests felt scrupulous individuals have a need for perfection possibly in order to avoid punishment: "got an idea that unless something is perfect you're condemned" (P4). Essentially, priests felt that scrupulous individuals trap themselves in a cycle of behaving scrupulously, possibly as a means to ensure they avoid punishment from what they see as an authoritarian God: “creates a sort of vicious cycle, as soon as they've gone out of the confessional they...immediately I've sinned again and I've got to go back in again" (P6). At the same time, such individuals were construed as constantly feeling unworthy and this prevents them from ever believing they have achieved perfection: "she's quite convinced that she's not right with God, she's unworthy to go to communion, that she's offending God in all sorts of ways" (P5). Given such individuals feel they are not loved by God, or are not worthy of God's love, then they must work harder to obtain this love. Hence, a need for perfection coupled with fixed beliefs about sin results in scrupulous individuals repetitively confessing to ensure they have perfectly confessed all their sins. Priests reported that a fixed belief system and a need to strive for perfection contributes to a vicious cycle from which the individual is unable to break free, leading to feelings of misery and unworthiness. Priests suggested these negative feelings might extend to how 
scrupulous people feel about other roles in their lives: "does she think she is not a good mother?" (P3). Priests placed importance on building up self-esteem and showing scrupulous individuals that they are worthy of love from family and from God.

However, a factor complicating this is encapsulated in the second subtheme of alienation. Priests considered the impact of this vicious cycle on others, both in general terms and in relation to the impact on the religious life of others, for example offspring. Priests suggested that children may become scrupulous themselves because they may believe their parent's behaviour was expected. On the other hand, participants wondered if "they become sort of anti-religion" (P4). In general terms, scrupulosity was seen to impact on relationships, such as intimacy with a spouse or by limiting interaction with children: "if this person is spending all this time in church she obviously is spending very little time with her two children" (P8). Priests envisaged that increased social isolation would add to the vicious cycle and hence perpetuate scrupulous acts: "people are not going to communicate with her, she's going to get more isolated, she's going to spend more of her time going into herself and turning it all over in her mind, and so it is all sort of compounded." (P6). There was a belief amongst the priests that such individuals would have few healthy relationships in their lives due to their fixed beliefs about sin.

The subtheme strict experiences reflects priests' consideration of the origins of the scrupulous individual's fearful world view. Priests suggested that the problems were not inherently caused by the church, feeling instead that they may be due to past experiences some of which may be encountered in the church context:

"I find that a lot of people who have real problems with confession are people who for whatever reason, and it may often be how they were taught as a child, 
the experiences they may have had within the church, which could perhaps be quite negative ones, that can lead them to, for instance, that when they think of God they are thinking of a sort of policeman type ... looking out for what they are going to do that's wrong" (P6).

Priests also suggested that scrupulous individuals may have experienced a strict upbringing and one in which they might never have felt forgiven by parents or felt that they had to work really hard to achieve forgiveness. This may have been combined with strict religious schooling which gave the scrupulous person a very rigid and fearful view of the church.

\section{(2) Restoring a more balanced view of the self-religion relationship}

This theme reflects priests' views on how they might help the scrupulous individual and links to the core concept in that suggestions were broadly focused on ways in which a rigid and fearful worldview might give way to more fluidity and balance. This was seen by priests to be achieved optimally by establishing a sound supportive relationship with the scrupulous person. Hence, the subtheme - building a supportive relationship reflects the importance of challenging and changing scrupulosity by way of the priest-

parishioner relationship. All priests spoke about the need to build a relationship with scrupulous individuals outside of the confessional:

"I'd want to do it very informally and I'd want to, you know, and she's used to seeing me, you know, all dressed up to the nines in church or sitting in the judgement seat as 
she's seeing it...I'd much rather she came in after and put the kettle on and just sort of relax a bit" (P9).

The construction of an extra-confessional relationship between priest and parishioner was felt by some to be essential in allowing the person to have a more healthy experience of the church and their religion, and an experience of a healthy religious relationship in their lives. At the same time, some spoke of the utility of actively using the priest's authority because the scrupulous person may be more likely to listen to a priest and act on their instructions. Some, however, recognized that the use of authority in this way might transfer the fearful view onto the priest which might result in scrupulous adherence to the perceived wishes of the priest. In considering the development of a relationship between priest and parishioner, a dilemma was evident in that the confession is bound by a seal which inhibits the priest from mentioning anything said in confession outside of it. Therefore, if the individual did not choose to see the priest outside of confession then, as one priest said, "my hands are tied I can't do anything" (P3). Having speculated that the origins of scrupulosity might involve experiences and beliefs related to childhood and also the importance of current relationships in maintaining and exacerbating issues, priests felt that the necessary exploration of these issues could not be done within the confessional. Sometimes, this was due to physical space: "I find in the confessional normally, well at least in this church, we have a grille now. I find with this sort of situation, that can be very inhibiting, it doesn't facilitate a more natural and deeper exploration of a person's situation" (P6). Importantly, often the inability to explore deeper issues might be due to the scrupulous person's drive for reassurance-seeking: “if one priest doesn't seem to take her seriously 
she'll go to another priest and another" (P1). This was perceived to have a profound effect on the priests' ability to build a relationship with and challenge an individual. Priests felt that the scrupulous person needs some distraction from their anxieties and excessive praying, but felt that there were dilemmas as to how they might approach this. Some felt that involvement in church activities may be counter-productive and could be discouraged. Yet, it was also evident that priests did not feel they could dissuade an individual from participating in the church as it could be their only support system.

The second subtheme - spiritual direction - referred to the priests' view of their role in challenging the fearful worldview of scrupulous parishioners. Priests spoke about the importance of religious education in this respect. This might focus on:

"looking at the sacrament of reconciliation and saying, right within the sacrament of reconciliation God forgives us, and when you come and confess your sins to the priest the priest acts on behalf of the community, so the community and the people hurt, at that point we believe in this church you were forgiven." (P3).

Priests suggested that the scrupulous person would need instruction about prayer and God's love for them and priests would avoid focusing on sin. Priests suggested the use of the scriptures and the sacraments as a way to achieve this education, choosing stories to help the individual realise they are loved by God and are worthy of this, as articulated by the following priest:

"I might get her to repeat to herself very simple prayers or simple phrases from the Scriptures of the Psalms that would help her to connect with this God and help her to feel that she's okay, you know" (P10). 


\section{(3) Achieving an interface with mental health services}

Having emphasized the importance of their relationship to the scrupulous person and the recognition of spiritual guidance in helping the person achieve more balance, priests also acknowledged that the problems presented by scrupulous people required psychological intervention due to their excessive and maladaptive nature: "scrupulosity is obsessive thinking which has a sort of religious focus" (P5). As such, priests were concerned that they lacked skills in working with these problems: "it's very difficult, from my experience anyway, to know how to help, how to deal with this" (P8) and "once you say this is an illness you see it's out of your expertise" (P2). Some priests were concerned that they could make the situation worse. What was difficult for the priests, in this context, was the recognition that they could not disengage from the relationship despite feeling ill-equipped to manage: "I'm not sure I know how to approach it frankly, but anyway I sort of don't have the choice" (P6). As one priest noted, attendance to pastoral needs can be "very tiring and taxing and it can get you down" (P8).

The subtheme - barriers to mental health involvement - reflects the priests' recognition of the opportunities provided by mental health service involvement but also the tensions in making this happen. Priests indicated they would suggest professional help to the person (e.g. GP consultation), stating the importance of being able to recognize the limits of their expertise and when they may need to suggest other help: "if the priest felt that he wasn't able to solve it then he would have to be able to say I've come to the point where I've got to pass it on." (P2). Priests viewed psychological help as beneficial and judged that mental health professionals would have the expertise and training to identify 
the problem: "I trust that they would have the skills to understand where that might be coming from and how to get her to address it" (P9). Nevertheless, issues of consent and confidentiality were keys barriers to this. If priests were to speak to a professional or make a referral, they would need to gain consent: "I don't know but I don't think that these conversations should take place without the permission of the person" (P10).

Although viewing psychological help as beneficial, priests did wonder that, due to the very nature of their problems, scrupulous people would not even see that they had problems or would be unable to listen to those trying to help them: "some people in these sort of situations simply don't listen" (P4). Significant concerns were expressed about fear of therapeutic work. Priests considered that therapeutic engagement would be hindered by the scrupulous person's fears that it could make them less religious because it might lead them to wonder: "is the psychologist asking me to lessen the depth of my commitment" (P5). There were also concerns that the person may believe they would be misunderstood by a therapist. Priests suggested a religious therapist may help overcome these barriers and hold a better understanding of the problems. Also the person may be more accepting of the intervention if their therapist was religious: "I would think the most, the ideal sort of therapist, might be someone who can link into that sort of experience of life and have an empathy in that respect, but you can't say it is essential" (P6). This participant suggested it might be sufficient that a non-religious therapist gain knowledge about religion:

"right well in the first place they would have to do some studying into the practices of the Catholic church and particularly into the areas of confession, what the church teaches about and what the church really teaches" (P6). 
Some priests felt that if the person was willing to accept professional help and had accepted they had a problem, then the religion of the therapist would not be important. Of more importance would be their psychological skills. However, some warned that a therapist could not be anti-religion and would not be able to dismiss religion in the therapeutic work.

The second subtheme - collaborative working - encapsulates priests' views of how barriers to mental health involvement might be overcome. Priests would value the sharing of information between the priest and the therapist, where both would benefit from the other's experience: "we may be able to share experience with each other and help each other and support each other in it" (P8). Few mentioned the benefits of working jointly in the room with the therapist but those who did indicated the priest's role as a provider of support to the client in that context. The need for training to ensure the effectiveness of joint sessions was highlighted.

\section{Discussion}

In this section, an overview of the emerging conceptual framework is given along with discussion of key findings and associated future research directions. Following this, study limitations are addressed.

\section{Overview of emerging conceptual framework}

The central concept was that scrupulosity was viewed as a rigid and fearful view of self,

God, and world. This had come about by way of the development of an unhealthy view of religion, most likely due to strict religious and parental experiences in childhood. The 
fearful worldview culminates in the scrupulous person having an authoritarian view of God and a very restrictive view of religion and spirituality. This produces a focus on sin and on making amends for perceived transgressions. Underpinning the impetus to make good is an essential belief in the self as unworthy of love, particularly God's. Efforts at making good (e.g. repeated confession) inevitably do not work and a vicious cycle is created whereby the person is unable to feel worthy yet tries hard to achieve love. The focus on sin and making amends also reinforces an unhealthy view of religion (i.e. as unforgiving and demanding). An inevitable result of being scrupulous is isolation from friends and family and anyone who might hold up an alternative and more benevolent view of self and religion.

Priests might intervene in these problems by way of spiritual re-education but there are significant challenges in establishing and maintaining an appropriately supportive relationship with the scrupulous person outside of the confessional. Relationships are undermined by the reassurance-seeking attempts of scrupulous people. Priests recognise the need and value of mental health input but barriers to this are fear of therapy on the part of the potential client, and maintaining a trusting and confidential relationship between priest and parishioner. Collaborative working is seen as one way to meet the challenges presented by the religion-mental health interface.

\section{Discussion of findings}

In addressing the research questions, the findings from the present study will be discussed within two broad areas: how scrupulosity is understood by Catholic priests and the challenges in working with people with scrupulosity, individually and 
collaboratively. In doing this, suggestions for research to further develop and test the emerging conceptual framework will be given.

\section{How is scrupulosity understood by Catholic priests?}

Overall, priests viewed scrupulous behaviour as a religious manifestation of OCD. Indeed, the core themes elaborated in the framework presented here map onto central phenomenological themes in OCD: the self as flawed or defective, a drive for reassurance-seeking/neutralizing that is inevitably counterproductive, and a position of isolation. The framework presented is similar to cognitive models of OCD that emphasise cycles of anxiety management characterized by doubt, and fear and activity to prevent bad outcomes. Some thought appraisal models in OCD seem particularly relevant to scrupulosity, particularly moral thought-action fusion (e.g. Shafran et al, 1996). And yet, given widespread religious observance, what makes some religious people more susceptible to such appraisals? The priests in this study speculated on early parental or religious experiences characterized by strictness. There has been some, albeit limited, theorizing and research regarding parental style and the development of OCD (e.g. Rachman \& Hodgson, 1980) with most of the focus being on parental overprotection and control. To our knowledge there is no research looking at family context specifically in scrupulosity although Miller and Hedges (2008) theorise that observational learning and stern family and religious contexts may be involved in the development of scrupulosity in childhood. Given issues with retrospective recall bias, triangulation of data sources from different informants may be beneficial. More broadly, 
we agree with Nelson et al's. (2006) suggestion that future research should explore the process of belief acquisition in scrupulous individuals.

It is evident from this study and from the literature that scrupulous individuals would seek out religious leaders for support and guidance and that, very often, religious leaders might be the sole source of support for the scrupulous individual. This places a significant burden on religious leaders who report feeling ill-equipped to know how to intervene in what they consider a mental health problem. Some priests in this study reported it difficult to maintain an appropriately supportive relationship in the face of reassurance-seeking from scrupulous individuals and some reported a belief that such individuals do not listen to guidance. This accords with Miller and Hedges' (2008) assertion that scrupulous individuals may remain unresponsive to reassurance from authoritative sources. The findings here suggest that individuals actively 'shop around' for priests who might support their scrupulosity. Previous research has highlighted the work-related stresses experienced by religious leaders and their need for support (Frances, Louden \& Rutledge, 2004; Weaver, Flannelly, Larson, Stapleton \& Koenig, 2002). The priests in this study indicated the difficulties of working with scrupulous individuals, a considerable strain being the requirement to engage with such individuals. This resonates with Leavey et al's. (2007) findings that the management of complex and serious mental health issues by clergy may result in guilt due to the conflict between vocation and self-protection. This may be especially keen in scrupulosity given the reluctance of individuals to seek other sources of support, and creates a potential conflict between a priest's sincere desire to respond to parishioners seeking help from them and an awareness of the limitations on their ability to actually deliver meaningful help. 
Consequently, future research could explore how priests can access support and the role that mental health services can play in supporting priests who deal with scrupulous individuals.

\section{Challenges in working with people with scrupulosity}

Despite the similarities drawn between OCD and scrupulosity, a key distinction is the potentially ego-syntonic nature of scrupulosity as opposed to the ego-alien nature of obsessions and compulsions in OCD. Ego-syntonicity represents a key challenge to intervention, both by priests and by mental health services. Priests are likely to be consulted first by people with scrupulosity (Ciarrocchi, 1995), but given the egosyntonic nature of the problem, this consultation may be more in the order of how to be a better Catholic. If the priest fails to support this desire, the person may find another

priest. The priests did see themselves in the helping role for people with scrupulosity, but they appeared to lack clarity in how best to support individuals with scrupulosity. This may be in large part due to the conceptualization they held of scrupulosity as both a spiritual and psychological problem. This accords with findings of Leavey et al. (2007) that some clergy emphasise using spiritual and medical intervention in parallel. Priests stated they would use 'spiritual direction' as a means to support the individual, but as they viewed this behaviour as a psychological illness, they did not feel skilled in managing such illnesses, which confirms the findings of Leavey et al. (2007) that religious leaders do not feel confident dealing with mental health problems. The priests were skilled within the spiritual domain and they suggested they could do this work alongside therapeutic work. The priests raised possible barriers that mental health 
workers might face in engaging individuals with scrupulosity, which included fearing they may not be understood and they agreed collaborative working could be a way to overcome this. Previous literature has suggested that professionals can overcome their lack of religious knowledge by working collaboratively with religious leaders (Abramowitz, 2001; Ciarrocchi, 1998). Confirming the view of one of the priests in this study, Burt and Rudolph (2000) suggest that it is not necessary for therapist-client dyads to be similar in religious background; instead, it is important the therapist is nonjudgmental and open to learning about religious issues. Such clinicians, they suggest, will also become adept at distinguishing normative religious beliefs and practice from psychopathology. As this study highlights the lack of mental health knowledge that priests feel they have, collaborative working could be beneficial to both parties and could form the basis of a psycho-spiritual approach, which could include joint working, consultation or offering reciprocal training. Miller and Hedges (2008) point out that sufficient collaboration between religious leaders and clinicians is rarely achieved. Future research effort could be expended on developing and testing frameworks for collaborative education and casework. However, in considering the development of collaborative frameworks for different religious groups or for individuals with differing levels of devotion, the work of Greenberg and Shefler (2008) is instructive. Following their review of rabbinic writings, these authors draw attention to issues regarding the lack of authority of mental health workers to give guidance over religious law to ultraorthodox Jews and hence the necessary involvement of the client's rabbi in the treatment process. Their review indicates preliminary evidence that the guidance of rabbis is congruent with a cognitive-behavioural approach to religious obsessions. 


\section{Clinical Implications}

This study highlights a potential lack of clarity about service delivery and pathways for individuals with scrupulosity. Priests in this study conceptualized scrupulosity as a mental health problem and in this construction felt less skilled to manage these individuals. They agreed that a more collaborative, psycho-spiritual approach would be beneficial, although they were unclear as to how this may occur in practice. The priests spoke of strengthening the individual spiritually and suggested using scripture as a means of doing this. Therapeutic work would have the aim of strengthening the individual's psyche. The shared goal would be to reduce the individual's distress and maladaptive behaviours. The findings suggest the value of 'psycho-spiritual' case discussions, allowing consultation to occur between religious leaders and mental health professionals. In this regard, Nelson et al. (2006) suggest that clergy could be involved in meetings between therapist and patient in order to confirm the notion that unwanted thoughts are not equivalent to committing sinful acts and the importance, prior to this, of the therapist conveying the problematic nature of the patient's maladaptive assumptions around thought to the clergy member. Strategies to facilitate collaboration might include the involvement of priests in mental health training and trainee therapists making contact with local religious leaders in order to establish some joint working at a training level. Therapists and priests could also offer training to each other, both at the seminaries and in the parishes and religious communities. Referral pathways can impact on priests' ability to gain support from mental health services for their parishioners. It may be necessary to address these pathways to make the route more accessible for religious 
leaders to ensure they and their parishioners attain appropriate support. However, consent and confidentiality will be key issues to resolve in this context.

Currently, cognitive-behavioural therapy has been proposed as the intervention for scrupulosity, but the limited literature presents variable success with these techniques (Abramowitz, 2001; Ciarrocchi, 1998; Greenberg, Witztum \& Pisante, 1987). However, recent work by Huppert, Siev and Kushner (2007) sets out a detailed adaptation to exposure and response prevention techniques in working with orthodox Jewish patients with scrupulosity. Their adaptation encompasses direct solutions to some of the challenges raised in this paper such as accepting treatment from non-religious individuals, conceptualization of the problem that is sensitive to the client's religious life, and the active use of doctrine to encourage treatment motivation. Preliminary data reported by these authors indicate rates of improvement and drop out using these modified techniques that are similar to rates reported in other studies of exposure and response prevention. Importantly, the approach is well tolerated by the Orthodox Jewish community. It would be important to apply modified principles to working with scrupulous individuals from other faith groups and evaluate their effectiveness. Mental health professionals and priests are skilled in formulating problems, within psychological and/or spiritual/theological frameworks. It would be fruitful if therapists and religious leaders could come together to locate scrupulosity within a formulation to determine effective psycho-spiritual interventions for scrupulous clients from different religious groups, and that they conducted joint research projects to evaluate such interventions. 


\section{Limitations}

The model developed in this study would have been influenced by those who agreed to participate and it may be that those who felt most comfortable and able to discuss issues around scrupulosity participated. It is possible these priests may have not held representative views about scrupulosity, the church and mental health services which may have contributed to their understanding of scrupulosity as a psychological disorder. Additionally, priests were not asked directly if they were aware of psychological models of working with scrupulosity, specifically cognitive-behavioural therapy (CBT). Therefore, it is not clear how much the current findings are influenced by knowledge of this treatment model. However, no priest in discussing interventions for scrupulosity made explicit reference to CBT. One priest did refuse to participate due to fear of breaking the seal of reconciliation and there may have been others who held similar views. These individuals may have given alternative perspectives to the understanding of scrupulosity and to the treatment and management suggestions, which limits the current model. However, this may highlight the difficulty collaborating with some priests who fear they may break the seal of reconciliation and, as such, therapists need to be respectful of this and encourage more neutral conversations to be held. This point cannot be understated given that canon law stipulates the inviolability of the seal of confession. A priest who directly breaches the seal risks censure by ecclesiastical court which might result in excommunication. Secular courts must uphold canonical prescriptions and, hence, priests may also face civil prosecution. This study focused on developing a conceptual framework of scrupulosity from the perspective of Catholic priests in South England, many of whom had experience of mental health services or 
specialized training. Evidence suggests that different faith groups vary in how much moral emphasis they give to thoughts (Abramowitz et al., 2002). As such, there is a need to research religious leaders from other faith groups, and those who have less experience of mental health training or contact with services. The perspective of scrupulous individuals is also not represented in the framework. In this regard, previous scrupulosity research involves those who have already sought professional help and hence are not representative of the individuals who may have sought help from their religious communities, or who may not seek help as they do not recognise they have a problem. Although it would be more difficult to recruit individuals reluctant to seek help, it would be important to ascertain the views of such people about their problems. This would help religious leaders and mental health professionals to consider appropriate support for these individuals that might be less intimidating or stigmatizing.

\section{References}

Abramowitz, J. (2001). Treatment of Scrupulous Obsessions and Compulsions Using Exposure and response Prevention: A Case Report. Cognitive and Behavioural Practice, $8,79-85$.

Abramowitz, J., Huppert, J., Cohen, A., Tolin, D. \& Cahill, S. (2002). Religious obsessions and compulsions in a non-clinical sample: The Penn Inventory of Scrupulosity (PIOS). Behaviour Research and Therapy, 40, 825-838. 
Benes, K.M., Walsh, J.M., McMinn, M.R., Dominguez, A.W. \& Aikins, D.C. (2000). Psychology and the church: An exemplar of psychologist-clergy collaboration. Professional Psychology: Research and Practice, 31, 515-520.

Burman, M.E., Stepans, M.B., Jansa, N. \& Steiner, S. (2002). How do NPs make clinical decisions? Nurse Practitioner, 27, 57-64.

Burt, V.K. \& Rudolph, M. (2000). Treating an orthodox Jewish woman with ObsessiveCompulsive Disorder: maintaining reproductive and psychologic stability in the context of normative religious rituals. American Journal of Psychiatry, 157, 620-624.

Ciarrocchi, J.W. (1995). The Doubting Disease. Help for Scrupulosity and Religious Compulsions. Mahwah, NJ: Paulist Press.

Ciarrocchi, J.W. (1998). Religion, Scrupulosity and Obsessive-Compulsive Disorder. In: M.A. Jenike, L. Baer \& W.E. Minichiello (Eds.). Obsessive-Compulsive Disorders ( ${ }^{\text {rd }}$ ed.). London: Mosby.

Edwards, L.C., Lim, B.R., McMinn, M.R. \& Domingues, A.W. (1999). Examples of collaboration between psychologists and clergy. Professional Psychology: Research and Practice, 30, 547-551. 
Frances, L.J., Louden, S.H. \& Rutledge, C.J.F. (2004). Burnout among Roman Catholic parochial clergy in England and Wales: Myth or Reality. Review of Religious Research, 46, 5-19.

Greenberg, D. (1984). Are religious compulsions religious or compulsive: a phenomenological study. American Journal of Psychotherapy, 38, 524-532.

Greenberg, D., Witztum, E. \& Pisante, J. (1987). Scrupulosity: religious attitudes and clinical presentations. British Journal of Medical Psychology, 60, 29-37.

Goldberg, D. \& Huxley, P. (1992). Common Mental Disorders: a Bio-Social Model. London: Routledge.

Greenberg, D. \& Shefler, G. (2002). Obsessive-compulsive disorder in ultra-orthodox Jewish patients: a comparison of religious and non-religious symptoms. Psychology and Psychotherapy: Theory, Research and Practice, 75, 123-130.

Greenberg, D. \& Shefler, G. (2008). Ultra-orthodox rabbinic responses to religious Obsessive-compulsive disorder. Israel Journal of Psychiatry and Related Sciences, 45,183-192.

Henwood, K. \& Pidgeon, N. (2003). Grounded Theory in Psychological Research. In: P.M. Camic, J.E. Rhodes \& L. Yardley (Eds.). Qualitative Research in Psychology: 
Expanding Perspectives in Methodology and Design. Washington, DC: American Psychological Association.

Huppert, J.D., Siev, J. \& Kushner, E.S. (2007). When religion and obsessive-compulsive disorder collide: treating scrupulosity in ultra-orthodox Jews. Journal of Clinical Psychology, 63, 925-941.

Jorm (1997). "Mental health literacy": a survey of the public's ability to recognise mental disorders and their beliefs about the effectiveness of treatment. The Medical Journal of Australia, 166, 182-186.

Leavey, G., Loewenthal, K. \& King, M. (2007). Challenges to sanctuary: The clergy as a resource for mental health care in the community. Social Science and Medicine, 65, 548559.

Marsh, R. and Low, J. (2006). God as other, God as self, God as beyond: a cognitiveanalytic perspective on the relationship with God. Psychology and Psychotherapy: Theory, Research and Practice, 79, 237-255

McMinn M. R., Aikins, D. C. \& Allen Lish,. R. (2003). Basic and Advanced Competence in Collaborating with Clergy. Professional Psychology: Research and Practice, 34, 197-202. 
Miller, C.H. \& Hedges, D.W. (2008). Scrupulosity disorder: an overview and introductory analysis. Journal of Anxiety Disorders, 22. 1042-1058.

Nelson, E.A., Abramowitz, J.S., Whiteside, S.P. \& Deacon, B.J. (2006). Scrupulosity in patients with obsessive-compulsive disorder: relationship to clinical and cognitive phenomena. Journal of Anxiety Disorders, 20, 1071-1086.

Neufeldt, S. A., Pinterits, E. J., Moleiro, C.M., Lee, T.E., Yang, P.H., Brodie, R.E. \& Orliss, M.J. (2006). How do graduate student therapists incorporate diversity factors in case conceptualization? Psychotherapy: Theory, Research, Practice, Training. Special Issue: Culture, Race, and Ethnicity in Psychotherapy, 43, 464-479.

Obsessive-Compulsive Cognitions Working Group (1997). Cognitive assessment of obsessive-compulsive disorder. Behaviour Research and Therapy, 35, 667-681.

Rachman, S \& Hodgson, R. (1980). Obsessions and Compulsions. Englewood Cliffs, NJ: Prentice Hall.

Sica, C., Novara, C., \& Sanavio, E. (2002). Religiousness and obsessive-compulsive congitions and symptoms in an Italian population. Behaviour Research and Therapy, 40, 813-823. 
Shafran, R., Thordarson, D.S. \& Rachman, S. (1996). Thought-action fusion in obsessive compulsive disorder. Journal of Anxiety Disorders, 10, 379-391.

Strauss, A. \& Corbin, J. (1998). Basics of Qualitative Research. Techniques and Procedures for developing Grounded Theory ( $2^{\text {nd }}$ ed.). London: Sage Publications.

Taylor, B.J. (2006). Factorial surveys: Using vignettes to study professional judgments. British Journal of Social Work, 36, 1187-1207.

Tek, C., \& Ulug, B. (2001). Religiosity and religious obsessions in obsessive-compulsive disorder. Psychiatry Research, 104, 99-108.

Thompson, T., Barbour, R., \& Schwartz, L. (2003). Adherence to advance directives in critical care decision making: vignette study. British Medical Journal, 327, 1011.

Weaver, A. J., Flannelly, K.J., Larson, D. B., Stapleton, C.L. \& Koenig, H. G. (2002). Mental health issues among clergy and other religious professionals: A review of research. Journal of Pastoral Care and Counselling, 56, 393-403.

West, P. (1982). Reproducing Naturally Occurring Stories: Vignettes in Survey Research. MRC Social \& Public Health Sciences Unit Working Paper. Medical Research Council. 


\section{Appendix 1. Scrupulosity vignette}

Jane is a mother of two. She has been married to her husband Bill for 12 years. Her husband works as a manager in a clothes shop. Now her children are at school she has a part time job working in the florist down the road. Jane and Bill are both Catholics, their children have been baptised and their eldest son is preparing for his holy communion. Jane is involved in some of the church activities. Every Saturday she goes to church to do the flowers. She helps run the children's liturgy on a Sunday morning, which her children attend. She attends the weekly bible study group and the prayer group. She worries about her husband, as unlike her he does not attend church regularly and she worries about the consequences of this. She goes to confession every Saturday and often asks for forgiveness on behalf of her husband.

Recently she has been spending longer in confession and many of her confessions focus on sins from her past. For example last week she confessed about an incident which occurred a year ago, where she walked past a young man, who was homeless and asked her for money. She explains that she felt a little unsafe and walked past him without giving him any money or offering any help. During the 'act of sorrow' she does not feel she has explained her sins correctly. She often feels the priest does not understand the severity of her sins and she finds it harder to believe that her sins have been absolved. She is increasingly spending longer after confession completing her penance and last week she had to be asked to leave after three hours as the church was being locked for the 
afternoon. When the church closed she did not want to leave and she returned as soon as the church opened later to resume her praying.

The lady who runs the children's liturgy with Jane came to speak to the priest. She is worried about Jane. She reported an incident in the children's liturgy, where Jane asked the children to repeat the "Sorry Prayer" five times as she did not think they had truly prayed. On the final occasion she asked everyone to repeat the prayer because a thought had popped into her own head to remind her to buy some more potatoes for dinner, and she felt she had not truly prayed and the prayer would not be heard. 
Table 1: Sample Characteristics

\begin{tabular}{|c|c|c|c|c|c|}
\hline \multirow[t]{2}{*}{ No } & \multicolumn{2}{|c|}{ Ordination } & \multirow[t]{2}{*}{ Ministry } & \multirow{2}{*}{$\begin{array}{l}\text { Had } \\
\text { personal } \\
\text { therapy }\end{array}$} & \multirow{2}{*}{$\begin{array}{l}\text { Has worked with } \\
\text { mental health } \\
\text { services }\end{array}$} \\
\hline & Year & Seminary & & & \\
\hline 1 & 1996 & England & Diocesan & No & Not stated \\
\hline 2 & $1958^{*}$ & Rome & Diocesan & No & Yes \\
\hline 3 & 1989 & Dublin & Diocesan & Yes & Yes \\
\hline 4 & $1962 *$ & Rome & Diocesan & No & Yes \\
\hline 5 & 1978 & England & Religious Community & Yes & Yes \\
\hline 6 & 1994 & England & Diocesan & Yes & No \\
\hline 7 & 1994 & England & Diocesan & No & Yes \\
\hline 8 & 1988 & Rome & Religious Community & No & Not stated \\
\hline 9 & 1997 & England & Diocesan & No & Yes \\
\hline 10 & 1968 & Dublin & Diocesan & Yes & Not stated \\
\hline 11 & 1977 & England & Diocesan & No & Not stated \\
\hline
\end{tabular}

*trained pre-Second Vatican Council 